\title{
Presentación atípica del síndrome de Gorham-Stout. Caso clínico
} Atypical presentation of Gorham-Stout syndrome. Case report

\author{
Estud. Alejandro González Luna ${ }^{a}$, Estud. Jorge Luis Nuñez Pizarro y Dr. Clodo Iván Rodríguez Echegaray ${ }^{b}$
}

\section{RESUMEN}

El síndrome de Gorham-Stout es una patología ósea extremadamente rara de etiología desconocida, caracterizada histopatológicamente por proliferación de los canales vasculares, que origina destrucción y resorción de la matrizósea. Se presenta el caso de un paciente varón de nueve años de edad con un cuadro agudo caracterizado por fiebre, dolor torácico, dificultad respiratoria y disnea ante pequeños esfuerzos. Se realizaron estudios de imágenes y patología, en los que se encontraron lesiones líticas múltiples y presencia de un linfangioma mediastínico. Se diagnosticó síndrome de GorhamStout. Esta es una presentación atípica debido a la localización de la linfangiomatosis y al tamaño de la masa.

Palabras clave: enfermedad de Gorham-Stout, osteólisis esencial, linfangioma.

\begin{abstract}
Gorham-Stout syndrome is an extremely rare pathology, of unknown etiology. It is characterized by proliferation of vascular channels that causes destruction and reabsorption of the bone matrix. We present a nine year-old male patient with an acute episode characterized by fever, chest pain, respiratory distress and dyspnea. The patient was submitted to computed tomography scan and a biopsy. The findings in the biopsy were multiple lytic lesions, osteolysis, and a mediastinal lymphangioma (lymphangiomatosis). The diagnosis was Gorham-Stout syndrome with atypical presentation.
\end{abstract}

Keywords: Gorham-Stoutdisease, essentialosteolysis, lymphangioma.

http:/ /dx.doi.org/10.5546/aap.2015.e153

\section{INTRODUCCIÓN}

El caso descrito es una presentación atípica del síndrome de Gorham-Stout (SGS) u osteólisis masiva idiopática. Esta enfermedad se encuentra dentro de un grupo de patologías caracterizadas por resorción ósea agresiva y extensa, que no

a. Escuela de Medicina, Universidad Peruana de Ciencias Aplicadas, Lima, Perú.

b. Servicio de Pediatría General del Hospital Nacional Edgardo Rebagliati Martins, Lima, Perú.

Correspondencia:

Jorge Luis Nuñez Pizarro: jorgeluisnp@gmail.com

Financiamiento: Ninguno.

Conflicto de intereses: Ninguno que declarar.

Recibido: 4-10-2014

Aceptado: 4-2-2015 respeta el límite óseo-cartilaginoso y se caracteriza por la proliferación anormal de vasos linfáticos. ${ }^{1}$ Fue descrita inicialmente por Jackson en $1838^{2}$ y acuñada más tarde por Gorham en $1955 .{ }^{3}$ Desde su descripción hace 60 años, la etiología de esta enfermedad se mantiene desconocida, y no se encuentra evidencia alguna de un componente maligno, neuropático o infeccioso. Sin embargo, se han propuesto diversas teorías en relación con su etiopatogenia. En primer lugar, se propuso la IL-6 como un factor importante para su desarrollo, ${ }^{4}$ debido a que se encontraron valores séricos elevados de esta citocina en pacientes en estadios tempranos de la enfermedad. En segundo lugar, se reportó la aparición de la enfermedad en un paciente con agenesia de las células $C$ tiroideas, ${ }^{5}$ por lo que se propuso la alteración en la secreción de calcitonina como un factor predisponente en el desarrollo de la enfermedad. Por último, recientemente, se resaltó la importancia de la cascada de señalización del PDGFR-b (receptor del factor de crecimiento derivado de las plaquetas, subunidad b) en el mecanismo patogénico de la enfermedad, ${ }^{6}$ lo cual debe ser corroborado en futuras investigaciones.

Las manifestaciones clínicas del SGS son variables y dependen del sitio de afección; siguen, generalmente, un curso crónico y progresivo. Además de las lesiones osteolíticas, concomitantemente, se puede presentar linfangiomatosis, que causa quilotórax, quiloperitoneo o quiloascitis y lesiones quísticas en órganos viscerales, especialmente en el bazo. ${ }^{7}$ Los criterios diagnósticos son los siguientes: a) biopsia positiva; b) ausencia de atipia celular; c) mínima o nula respuesta osteoblástica y ausencia de calcificación distrófica; d) evidencia de resorción ósea progresiva; e) lesiones no expansivas y no ulcerativas; f) ausencia de afectación visceral; g) patrón osetolítico radiográfico; h) sin causa hereditaria, metabólica, inmunológica o infecciosa. ${ }^{7}$

El tratamiento no es curativo e incluye la radioterapia, medicación antiosteoclástica e interferón alfa-2b. La radioterapia es la terapia 
más efectiva al reducir la progresión de la enfermedad en un $77-80 \%$ de los casos. ${ }^{8}$ No obstante, el interferón alfa- $2 \mathrm{~b}$ tiene actividad antiangiogénica e inmunomoduladora, que disminuye los niveles circulatorios de la IL-6 $y$, por ende, inhibe la proliferación anómala de vasos sanguíneos. ${ }^{9}$ Además, los bifosfonatos han demostrado ser beneficiosos para esta patología. En esta enfermedad, se crea un desbalance entre la actividad osteoblástica y osteoclástica, por lo que los bifosfonatos, al incrementar la apoptosis de los osteoclastos y disminuir su actividad, estabilizan el progreso del cuadro. ${ }^{9}$

\section{PRESENTACIÓN DEL CASO}

Se presenta un paciente varón de nueve años, con un tiempo de enfermedad de 12 días, caracterizado por fiebre $\left(\mathrm{T}^{\circ}:>38^{\circ} \mathrm{C}\right)$, dolor torácico, dificultad respiratoria, disnea ante pequeños esfuerzos e hiporexia. Los síntomas se incrementaron en intensidad, por lo que acudió a un centro hospitalario donde se realizó una tomografría espiral multicorte (TEM) torácica y se evidenció una masa mediastinal de aspecto neoproliferativo y múltiples imágenes nodulares hipodensas en el bazo (Figura 1). Se planteó el diagnóstico de tumor mediastinal de etiología por determinar, para descartar linfoma no Hodgkin, y se derivó a un centro de salud de mayor complejidad. Como antecedente patológico, refirió una cirugía de cuello a los tres meses de edad por exéresis de tumoración con diagnóstico histopatológico de higroma quístico; negó otros antecedentes de importancia.

FIgURA 1. Imagen topográfica toracoabdominal sin contraste: lesiones osteoliticas en el cuerpo vertebral (flecha roja) y múltiples imágenes hipodensas en el bazo (flecha azul)

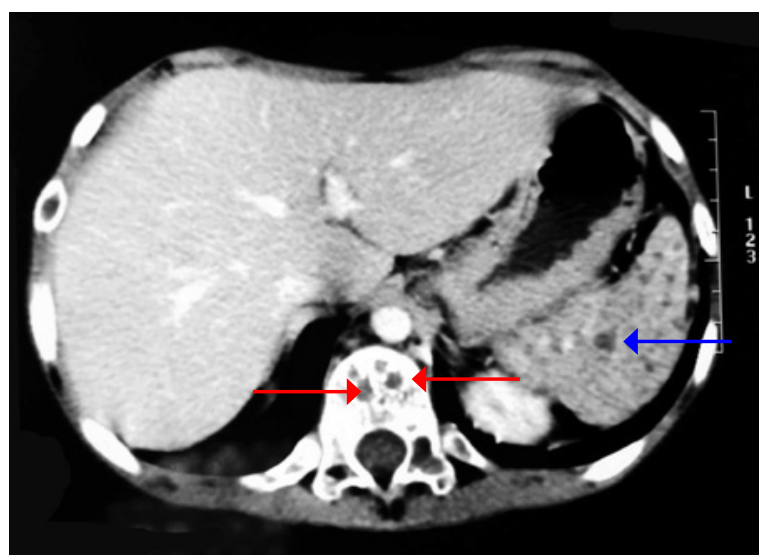

El paciente fue evaluado por el Servicio de Hematología. Se realizó aspirado de médula ósea, cuyos hallazgos fueron normales. Posteriormente, se realizó TEM de cuello, tórax y pelvis, en la que se encontraron imágenes hipodensas de aspecto osteolítico a nivel de los cuerpos vertebrales de la columna, los arcos costales, el esternón, los huesos ilíacos, el sacro y alteración de la médula ósea del húmero derecho (Figura 1), lo cual coincidiría con la densitometría ósea que se realizó posteriormente (Tabla 1). Además, se evidenció amplia formación hipodensa líquida tabicada, que ocupaba el espacio mediastinal anterior y se proyectaba en las regiones anteriores del hemitórax, la región infraesternal y retroclavicular derecha con presencia de delgados septos internos, e involucraba los vasos mediastinales, troncos venosos braquiocefálicos, vena cava superior, parte del cayado aórtico y aorta ascendente (Figuras 2 y 3). Asimismo, se realizó un estudio óseo y se encontraron

Tabla 1. Densitometría ósea

\begin{tabular}{lcccc}
\hline Región & Área $\left(\mathrm{cm}^{2}\right)$ & CMO $(\mathrm{g})$ & DMO $\left(\mathrm{g} / \mathrm{cm}^{2}\right)$ & Puntaje Z \\
\hline L1 & 8,27 & 2,38 & 0,288 & $-3,2$ \\
L2 & 8,97 & 3,01 & 0,335 & $-3,6$ \\
L3 & 9,31 & 3,01 & 0,323 & $-4,0$ \\
L4 & 8,99 & 3,61 & 0,402 & $-2,7$ \\
\hline
\end{tabular}

CMO: concentración mineral ósea. DMO: densidad mineral ósea.

FIGURA 2. Imagen tomográfica de tórax con ventana mediastinal sin contraste: se aprecia masa mediastínica (flecha roja)

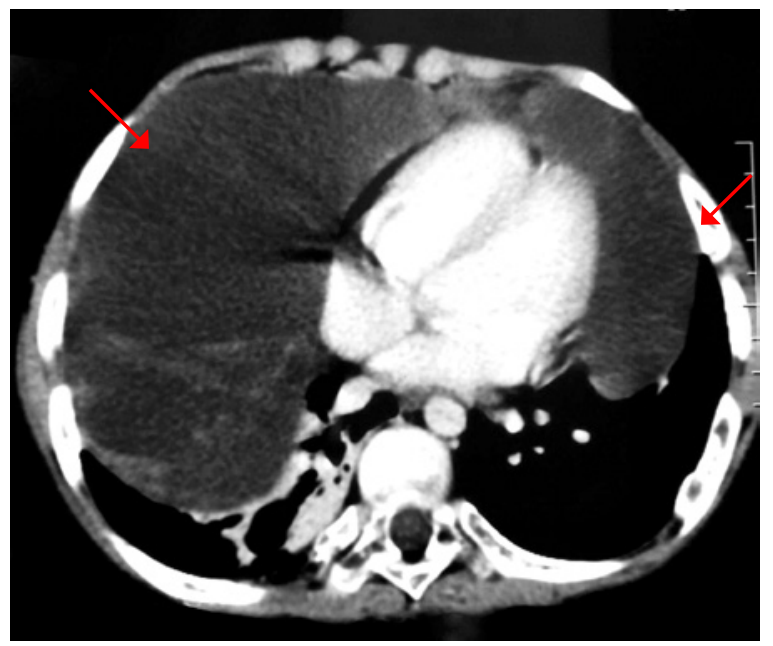


imágenes líticas, múltiples en huesos, sugestivas de metástasis. Días después, se realizó punción, drenaje y biopsia de la tumoración mediastínica. El informe describió: "Negativo para células tumorales. Elementos sanguíneos con infiltrado linfocitario y macrófagos compatible con quiste benigno. Diagnóstico: lesión benigna vascular compatible con linfangioma, en correlación con el cuadro clínico y las imágenes radiológicas correspondiente a una linfangiomatosis".

Luego el paciente presentó diversos episodios similares al motivo de ingreso, y se encontró, en el examen físico, murmullo vesicular abolido en el hemitórax anterior derecho. Por este motivo, se le realizaron diversos exámenes complementarios, y solo se encontraron transaminasas TGO/ TGP elevadas y hemocultivo positivo para Staphilococcus cohnni. Finalmente, se programó una escisión quirúrgica de masa mediastinal por esternotomía. Se ingresó a Unidad de Cuidados Intensivos y se inició tratamiento con ceftazidima, vancomicina, metronidazol, interferón alfa-2b, propanolol, carbonato de calcio y ácido zoledrónico. Desafortunadamente, días después, los padres del paciente revocaron el consentimiento informado para la realización de la cirugía y solicitaron el alta voluntaria, a pesar de haberlos asesorado sobre las posibles consecuencias de esta decisión. No se pudo contactar posteriormente al paciente o a sus familiares para conocer su evolución.

FIGURA 3. Tomografía computarizada de tórax con contraste intravenoso. Ventana de parénquima pulmonar. Se aprecia masa mediastínica (flecha roja)

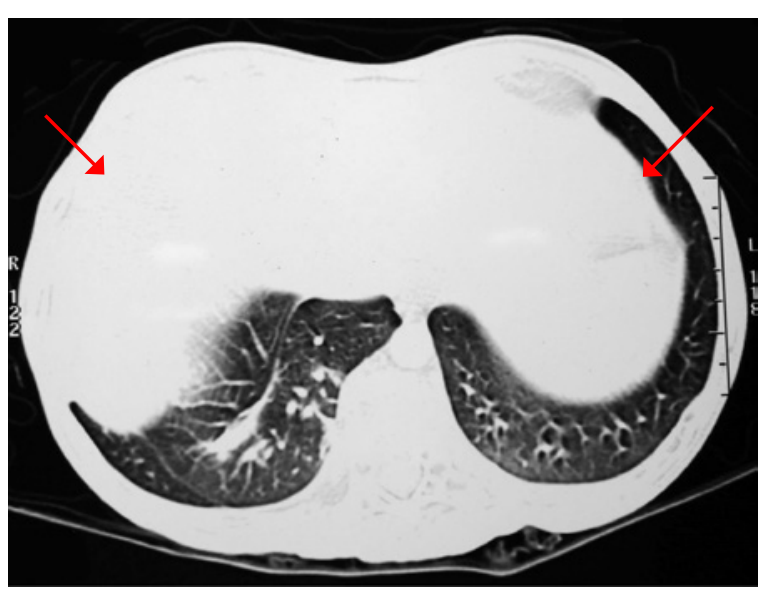

\section{DISCUSIÓN}

El caso reportado constituye una presentación atípica del síndrome de Gorham-Stout. Esta enfermedad es muy poco frecuente; a la fecha, se han reportado menos de 300 casos..$^{10}$ Además, menos del 1\% de los casos de linfangiomatosis se presentan en el mediastino y muy pocos de estos casos se han presentado asociados al síndrome de Gorham-Stout. ${ }^{11}$ Asimismo, a pesar de que el criterio diagnóstico requiera evidencia de resorción ósea local, este tipo de presentación, caracterizado por resorción ósea difusa en cuerpos vertebrales, arcos costales, esternón, iliacos y sacro, se ha descrito anteriormente en la literatura ${ }^{12}$ y debe ser incluido dentro de la sospecha en los pacientes que cumplan con los demás criterios diagnósticos.

Las características de la masa descrita en la tomografía (Figuras 1 y 2) concuerdan con las descritas en la bibliografía. ${ }^{11}$ Sin embargo, a pesar de encontrarse en un paciente pediátrico, su tamaño es comparativamente mayor. Además, es importante incluir dentro de las presentaciones clínicas el hecho de que la afectación de masa en la caja torácica puede evolucionar a síntomas y signos respiratorios causados por el efecto de masa y la infiltración de órganos vecinos. El quilotórax es una complicación infrecuente de este síndrome, pero que alcanza un 50\% de mortalidad. ${ }^{13,14}$ Esta es ocasionada por la infiltración del conducto torácico o del espacio pleural por vasos linfáticos displásicos. No obstante, a pesar del tamaño de la tumoración, no se evidenció la presencia de dicha complicación en el caso presentado.

No existe una terapia específica para esta patología. Sin embargo, a pesar de que el uso de radioterapia se considera el manejo más efectivo para la osteólisis, ${ }^{14}$ el uso de ácido zolendrónico e interferon alfa- $2 b$ ha demostrado beneficio en casos aislados. ${ }^{15}$ En el caso presentado, debido a que la distribución de la osteólisis y el estado del paciente no permitieron el uso de radioterapia, se inició tratamiento con ácido zolendrónico e interferon alfa-2b.

En conclusión, a pesar de la baja incidencia de esta enfermedad, son necesarios nuevos estudios que caractericen este amplio síndrome y establezcan nuevas alternativas terapéuticas.

\section{REFERENCIAS}

1. Moller G, Priemel M, Amling M, Werner M, et al. The Gorham-Stout syndrome (Gorham's massive osteolysis). A report of six cases with histopathological findings. J Bone Joint Surg Br 1999;81(3):501-6. 
2. Jackson JBS. A boneless arm. Boston Med Surg J 1838;18:368-9.

3. Gorham LW, Stout AP. Massive osteolysis (acute spontaneous absorption of bone, phantom bone, disappearing bone): its relation to hemangiomatosis. J Bone Joint Surg Am 1955;37-A(5):985-1004.

4. Devlin RD, Bone HG 3rd, Roodman GD. Interleukin-6: a potential mediator of the massive osteolysis in patients with Gorham-Stout disease. J Clin Endocrinol Metab 1996;81(5):1893-7.

5. Korsi M, Jelasi D,PotockiK, Gilievi Z,Aganovi I. Massive osteolysis in a girl with agenesis of thyroid C cells. Skeletal Radiol 1998;27(9):525-8.

6. Hagendoorn J, Padera TP, Yock TI, Nielsen GP, et al. Platelet-derived growth factor receptor-beta in Gorham's disease. Nat Clin Pract Oncol 2006;3(12):693-7.

7. $\mathrm{Hu} \mathrm{P}, \mathrm{Yuan} \mathrm{X}, \mathrm{Hu} \mathrm{X}$, Shen F, Wang J. Gorham-Stout syndrome in mainland China: a case series of 67 patients and review of the literature. J Zhejiang Univ Sci B 2013;14(8):729-35.

8. Heyd R, Micke O, Surholt C, Berner B, et al. Radiation therapy for Gorham-Stout syndrome: results of a national patterns-of-care study and literature review. Int J Radiat Oncol Biol Phys 2011;81(3):e179-85.
9. Avelar RL, Martins V, Antunes A, Neto PJ, Andrade E. Use of zoledronic acid in the treatment of Gorham's disease. Int J Pediatr Otorhinolaryngol 2010;74(3):319-22.

10. Orphanet Report Series. Prevalence of rare diseases: Bibliographic data. Listed in alphabetical order of disease or group of diseases. May 2014 - Number 1. [Acceso: 6 de febrero de 2015]. Disponible en: http:/ /www.orpha. net/orphacom/cahiers/docs/GB/Prevalence_of_rare_ diseases_by_alphabetical_list.pdf.

11. Brown LR, Reiman HM, Rosenow EC $3^{\text {rd }}$, Gloviczki PM, Divertie MB. Intrathoracic lymphangioma. Mayo Clin Proc 1986;61(11):882-92.

12. Yava o lu , Çakiro lu U. Diffuse Lymphangiomatosis: Gorham-Stout Syndrome. Intern Med 2014;53(1):75-6.

13. Seok YK, Cho S, Lee E. Early surgical management of chylothorax complicated by Gorham's disease. Thorac Cardiovasc Surg 2010;58(8):492-3.

14. Fujiu K, Kanno R, Suzuki H, Nakamura N, Gotoh M. Chylothorax associated with massive osteolysis (Gorham's syndrome). Ann Thorac Surg 2002;73(6):1956-7.

15. Kuriyama DK, McElligott S, Glaser D, Thompson K. Treatment of Gorham-Stout disease with zoledronic acid and interferon- : a case report and literature review. J Pediatr Hematol Oncol 2010;32(8):579-84. 